Article

\title{
Zwitterionic Polymer P(AM-DMC-AMPS) as a Low-Molecular-Weight Encapsulator in Deepwater Drilling Fluid
}

\author{
Xin Zhao ${ }^{1,2, *}$, Zhengsong Qiu ${ }^{1,2}$, Yongjun Zhang ${ }^{3}$, Hanyi Zhong ${ }^{1,2}$, Weian Huang ${ }^{1,2}$ \\ and Zhichuan Tang ${ }^{1}$ \\ 1 School of Petroleum Engineering, China University of Petroleum, Qingdao 266580, China; \\ qiuzs@upc.edu.cn (Z.Q.); zhonghanyi@126.com (H.Z.); masterhuang1997@163.com (W.H.); \\ teamo_tzc@163.com (Z.T.) \\ 2 National Engineering Laboratory for Testing and Detection Technology of Subsea Equipments, \\ Qingdao 266580, China \\ 3 Tianjin Ruiyang Offshore Engineering Company Limited, Tianjin 300450, China; \\ zhangyongjun_upc@163.com \\ * Correspondence: zhaoxin@upc.edu.cn; Tel.: +86-532-8698-3576
}

Academic Editor: Peter Van Puyvelde

Received: 9 April 2017; Accepted: 31 May 2017; Published: 8 June 2017

Featured Application: This work aims to simultaneously realize good encapsulation performance and low-temperature rheological property for deepwater drilling fluid. It is expected to be used in deepwater oil and gas drilling operations.

\begin{abstract}
In deepwater oil and gas drilling, the high-molecular-weight encapsulator aggravates the thickening of the drilling fluid at low temperatures. Therefore, it is hard to manage the downhole pressure, and drilling fluid loss occurs. In this paper, a zwitterionic polymer P(AM-DMC-AMPS) which was the terpolymer of acrylamide, methacrylatoethyl trimethyl ammonium chloride, and 2-acrylamido-2-methylpropane sulfonic acid, was developed as a low-molecular-weight encapsulator. It was characterized by Fourier transform infrared spectrum analysis, nuclear magnetic resonance, and gel permeation chromatography. Moreover, the low-temperature rheology, shale inhibition and filtration properties of water-based drilling fluids (WBDFs) containing different encapsulators were experimentally investigated and compared. The results showed that the molecular weight of P(AM-DMC-AMPS) was about 260,000, much lower than that of the conventional encapsulators. In the deepwater drilling temperature range $4-75^{\circ} \mathrm{C}$, WBDF containing P(AM-DMC-AMPS) had lower and more stable rheological property because of its short molecular chains. The high shale recovery rate and low swelling rate indicated its strong shale inhibition performance, owing to its adsorption on the clay surface and the wrapping effect through both hydrogen bonding and electrostatic interaction. It also improved the filtration property of WBDF, and was compatible with other WBDF components. This product is expected to simultaneously realize the good encapsulation performance and low-temperature rheological property for deepwater drilling fluid.
\end{abstract}

Keywords: low-molecular-weight encapsulator; deepwater drilling fluid; low-temperature rheological property; shale inhibition; filtration property; zwitterionic polymer

\section{Introduction}

Offshore deepwater regions are rich in oil, natural gas and gas hydrate resources. The drilling fluid is called the blood of drilling engineering [1], and it is extremely important for deepwater drilling operations. Shale in deepwater is water sensitive, so it is prone to hydration on exposure to filtrates of 
water-based drilling fluid (WBDF), thus causing wellbore instability [2-5]. Serious thickening of the drilling fluid occurs in deepwater drilling when it is cooled down by the low-temperature environment (approximately $4{ }^{\circ} \mathrm{C}$ ) [6-8], leading to operation troubles.

Salt/polymer WBDF was initially used in deepwater drilling operations in the Gulf of Mexico in the early 1990s [9]. The partially hydrolyzed polyacrylamide (PHPA) was used to inhibit the hydration of shales to maintain the integrity of cuttings as well as the wellbore stability. As the drilling operations moved into deeper water regions, the wellbore instability in water-sensitive shale formation and thickening of drilling fluid caused by the high-molecular-weight polymer PHPA made this WBDF unsatisfactory for deepwater drilling operations. Synthetic-based drilling fluid (SBDF) has the advantages of high penetration rate, wellbore stability, etc. However, field applications show that it is an extraordinary challenge in managing the downhole pressure, because the elevated rheology of drilling fluid at a low temperature leads to a high equivalent circulating density (ECD). Since the safe density window between the fracture pressure and pore pressure in deepwater drilling is very narrow, the substantial increase in ECD exceeds the safe density limit, resulting in loss circulation of drilling fluid $[6,10,11]$. The frequent lost circulation significantly reduced or eliminated the economic benefits. Moreover, there are environmental concerns on the use of SBDF for some regions. Therefore, WBDF is favored in consideration of environmental protection and costs, but the shale inhibition and low-temperature rheology problems related to the high-molecular-weight encapsulator are still big concerns.

In recent years, a high performance WBDF has been developed $[5,12,13]$, and it performs better than traditional WBDFs (water-based drilling fluids) in deepwater drilling. Owing to the development of a novel hydration inhibitor along with the use of encapsulator, the novel WBDF can achieve comparable shale inhibition to SBDF. Generally, the encapsulators for WBDF were the high-molecular-weight amide polymers, such as PHPA, polyacrylamide (PAM), and particular zwitterionic polymer [3,14-19]. They can form multi-point adsorption on the surface of clay particles on the wellbore by hydrogen bonding interaction of $-\mathrm{CONH}_{2}$ and other adsorption groups, and bridge the surrounding clay particles together and wrap them, thus preventing the dispersion and exfoliation of clay particles [13]. At the same time, the encapsulator can also maintain the integrity of drill cuttings in drilling fluid, enabling them to be easily removed by solid control equipment. Therefore, the high-molecular-weight (usually above 2,000,000) polymer is required to effectively bridge and wrap the clay particles [17]. However, the long molecular chains of these polymers result in high friction, and the curly molecular chains are prone to form grid structure through intertwining, and thus the WBDF thickens [20]. Particularly in deepwater drilling, the polymer molecular chains curl up and entangle with each other at a low temperature. Due to this, the viscosity and gel strength of WBDF substantially increase, so the ECD apparently increases, resulting in lost circulation. In addition, the viscous drilling fluid due to the presence of high-molecular-weight encapsulator at a low temperature usually adheres to the vibration screen and unable to get through the sieve, thus leading to drilling fluid leakage [21]. Since deepwater drilling is a high-risk and high-investment operation with a daily expense of approximately $\$ 1,000,000$, problems such as lost circulation and leakage of drilling fluid lead to huge economic loss, and increase security risks. The ideal deepwater drilling fluid should have both excellent shale hydration inhibition and low-temperature rheological properties. Therefore, at present, it is essential to solve the contradiction that the encapsulator with high-molecular-weight causes thickening of drilling fluid at a low temperature, while that with low-molecular-weight provides poor encapsulation performance. Experimental study showed that, when the molecular weight of conventional encapsulator was lower than 2,000,000, the encapsulation effect was not satisfactory [22]. As currently reported, in consideration of both the encapsulation and low-temperature rheological properties, the low-molecular-weight encapsulator product was developed and its molecular weight was about 900,000 [21,23]. Field applications showed that it mitigated the thickening of WBDF at low temperatures to some extent. However, at present, the rheology-related problem has not been completely solved and lost circulation of drilling fluid occurs 
frequently in deepwater drilling operations. Moreover, it should be noted that the latest encapsulator is a cationic polymer, which can neutralize the negative charge on clay surface and increase the stability of shale. However, there are concerns about the compatibility of cationic polymer with other components of WBDF, because sometimes serious flocculation of the drilling fluid occurs when cationic polymer is added $[24,25]$. Therefore, the molecular structure and molecular weight of the encapsulator need to be further optimized.

In this paper, to simultaneously realize the good encapsulation performance, low-temperature rheological property and compatibility of drilling fluid, a zwitterionic polymer P(AM-DMC-AMPS) with low-molecular-weight for deepwater drilling was developed. It was synthesized using acrylamide (AM), methacrylatoethyl trimethyl ammonium chloride (DMC), and 2-acrylamido-2-methylpropane sulfonic acid (AMPS) as the monomers, and was named SDCap as a commercial product for potential application in the future. Its feasibility on deepwater drilling was investigated through experimental evaluations of the low-temperature rheological property, shale inhibition and filtration property.

\section{Materials and Methods}

\subsection{Materials}

AM was purchased from Jinan Jinrihe Chemical Co., Ltd. (Jinan, China); AMPS was purchased from Zhengzhou Dingshengxin Chemicals (Zhengzhou, China); DMC was purchased from Jinan Duoxin Co., Ltd. (Jinan, China). Sodium hydrogen sulfite, ammonium persulfate and mercaptoacetic acid were purchased from Sinopharm Chemicals (Shanghai, China), and all these materials were analytically pure. All the drilling fluid additives used for preparing the testing WBDFs were provided by China Oilfield Services (Sanhe, China) and Shida Chuangxin technology Co., Ltd. (Dongying, China); sodium bentonite with a cation exchange capacity of $74 \mathrm{mmol} / \mathrm{g}$ was purchased from Boyou Bentonite Group Co. Ltd. (Weifang, China), and it consisted of $57.6 \%$ montmorillonite, $32 \%$ quartz, $8 \%$ potassium feldspar, $0.6 \%$ kaolinite, $1.2 \%$ illite, and $0.6 \%$ chlorite. Drilling fluid bentonite was purchased from Weifang Huawei Bentonite Group Co., Ltd. (Weifang, China), following the American Petroleum Institute (API) standard. For the shale recovery rate tests, the shale sample \#1 was obtained from the deepwater wells in the South China Sea, and it consisted of $23 \%$ clay, $45 \%$ quartz, $13 \%$ calcite, $10 \%$ anorthose, $4 \%$ dolomite, $4 \%$ halite, and $1 \%$ gypsum; the shale sample \#2 was obtained from wells in Bohai Bay, and it consisted of 25\% clay, $43 \%$ quartz, 20\% anorthose, $9 \%$ potassium feldspar, $2 \%$ dolomite, and $1 \%$ calcite.

\subsection{Preparation of SDCap}

The aqueous solution polymerization method [26] was used to prepare the SDCap. Under a stirring conditions, AM, AMPS and DMC with a mole ratio of 6:1:3 were added into a four-necked flask, wherein the solvent was deionized water. The mole ratio of the three monomers was determined by experimental investigations on the effects of monomer ratio on the molecular weight, cationic degree and the inhibition performance of the product. As the mole fraction of DMC increased, the molecular weight of the product decreased, whereas the cationic degree increased. As the mole fraction of AM increased, the molecular weight of the product increased, whereas the cationic degree decreased. The orthogonal tests showed that, when the monomer molar ratio was 6:1:3, the shale inhibition performance of the product was the best. A total concentration of the monomers was maintained to be $15 \%$, and oxygen was removed by purging the flask with nitrogen. The temperature was increased to $60{ }^{\circ} \mathrm{C}$, while $0.1 \%$ mixture of sodium bisulfite and ammonium persulfate was added as the initiator with continuous introduction of nitrogen. After $2 \mathrm{~h}$ reaction time, the reaction was terminated by the addition of mercaptoacetic acid. Then, a target product was obtained after extracted with acetone. The molecular structure was shown in Figure 1. 


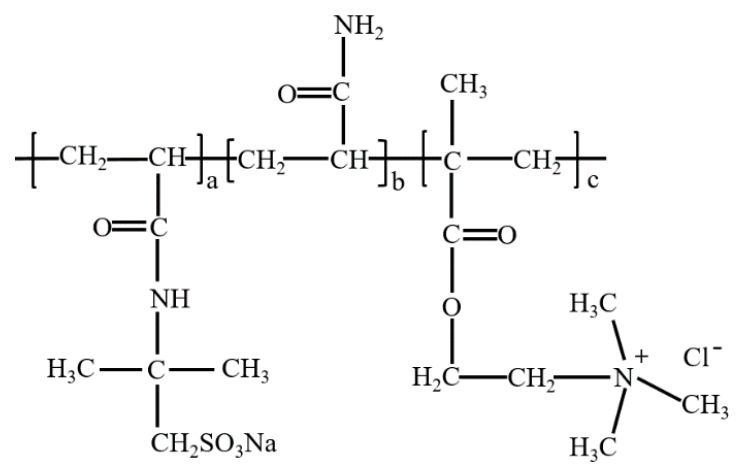

Figure 1. Molecular structure of SDCap (commercial name of P(AM-DMC-AMPS)).

\subsection{Characterization and Performance Evaluation}

\subsubsection{Characterization of the Product}

The Fourier transformation infrared (FT-IR) spectra of SDCap were recorded by a NEXUS FT-IR spectrometer (Thermo Nicolet Corporation, Denver, CO, USA), scanning from $4000 \mathrm{~cm}^{-1}$ to $400 \mathrm{~cm}^{-1}$. The nuclear magnetic resonance (NMR) spectra were recorded by a Bruker AVANCE III $400 \mathrm{MHz}$ spectrometer (Bruker BioSpin, Rheinstetten, Germany) using $\mathrm{D}_{2} \mathrm{O}$ as the solvent [27]. Gel Permeation Chromatography (Malvern 270 max GPC, Malvern Instruments, Malvern, UK) was used to determine the molecular weight of SDCap [28].

\subsubsection{Shale Inhibition Performance}

Shale recovery rate test has been designed to simulate the exposure of shale samples to the drilling fluid in the wellbore. The hydration dispersion of shale samples in water and drilling fluid could be evaluated, reflecting the inhibition effect of drilling fluid on the dispersion of clay particles. Mass of $40 \mathrm{~g}$ shale samples, which were screened with a 10-mesh and $280 \mathrm{~mL}$ test fluid, was added into the oven cell. After hot rolling for $16 \mathrm{~h}$, the solution containing shale samples were screened with a 40-mesh sieve. The remaining shale samples were dried at $105^{\circ} \mathrm{C}$ for $4 \mathrm{~h}$, and then weighed, and the recovery rate was determined $[14,16]$.

The linear swelling test has been designed to evaluate the swelling rate of shale in drilling fluid. The tests were conducted using a NP-2 swelling instrument (Haitongda, Qingdao, China) to measure the linear swelling rate of the core sample after immersed in pure water and drilling fluid $[29,30]$. Bentonite which was crushed and sifted through a 100-mesh screen, was used to prepare the core sample.

\subsubsection{Rheological Property}

The rheological properties of different WBDFs were measured at $4,25,50$ and $75{ }^{\circ} \mathrm{C}$, using a ZNN-D6 viscometer (Haitongda, Qingdao, China) with the API recommended standard procedure. The apparent viscosity (AV), plastic viscosity (PV) and yield point (YP) were calculated using the following equations [31].

$$
\begin{gathered}
\mathrm{AV}=0.5 \times \theta 600(\mathrm{mPa} \cdot \mathrm{s}) \\
\mathrm{PV}=\theta 600-\theta 300(\mathrm{mPa} \cdot \mathrm{s}) \\
\mathrm{YP}=0.5 \times(\theta 300-\mathrm{PV})(\mathrm{Pa})
\end{gathered}
$$

\subsubsection{Filtration Tests}

The API filtrate volume of the WBDF was measured by a ZNS-2A filtration apparatus (Haitongda, Qingdao, China) at $4{ }^{\circ} \mathrm{C}$ and $0.7 \mathrm{MPa}$ [32]. The high temperature and high pressure filtrate volume 
was measured by a GGS 42-1 HTHP filtration apparatus (Haitongda, Qingdao, China) at $150{ }^{\circ} \mathrm{C}$ and 3.5 MPa [27]. The surface morphology of filter cake formed by WBDF in API filtration tests was scanned using a S-4800 scaning electron microscope (Hitachi, Tokyo, Japan) [33,34].

\subsection{Inhibition Mechanism Analysis}

\subsubsection{Analysis of the Particle Size}

The particle size distribution of clay particles was measured using a Bettersize 2000 laser particle size analyzer (Dandong Bettersize instruments, Dandong, China) to study the influence of SDCap on the size distribution of clay particles [35].

\subsubsection{Analysis of Zeta Potential}

The surface charges of clay suspensions in the presence of different concentration of SDCap were measured using the zeta potential analyzer (Nano Brook Omni, Brook Heaven, NY, USA).

\subsubsection{Adsorption of SDCap on Bentonite}

Mass of $2 \mathrm{~g}$ sodium bentonite was added into the conical flask, and then $50 \mathrm{~mL}$ aqueous solution containing SDCap was added. The $\mathrm{pH}$ was adjusted to 8.5 . The suspension was agitated at $200 \mathrm{r} / \mathrm{min}$ for $24 \mathrm{~h}$, and then was separated by centrifugal elutriation. The concentration of SDCap in the supernatant was measured, and the adsorbance was calculated as follows $[36,37]$.

$$
\mathrm{A}=\left(\mathrm{C}_{0}-\mathrm{C}\right) \mathrm{V} / \mathrm{m}
$$

where $\mathrm{A}$ is the adsorbance, $\mathrm{mg}^{-1} \mathrm{~g}^{-1} \mathrm{~V}$ is the solution volume, $\mathrm{mL} ; \mathrm{M}$ is the mass of adsorbed bentonite, $\mathrm{mg} ; \mathrm{C}_{0}$ is the initial SDCap concentration, $\mathrm{mg} / \mathrm{L}$; and $\mathrm{C}$ is the concentration after absorption, $\mathrm{mg} / \mathrm{L}$.

\section{Results and Discussions}

\subsection{Characterization of SDCap}

The infrared spectrum results are shown in Figure 2. The $-\mathrm{NH}_{2}$ stretch vibration absorption peak and characteristic absorption peak appeared at $3416.3 \mathrm{~cm}^{-1}$ and $622.4 \mathrm{~cm}^{-1}$, respectively, while the $\mathrm{C}=\mathrm{O}$ characteristic absorption peak in amide groups appeared at $1665.9 \mathrm{~cm}^{-1}$, indicating that the AM chain segments existed in the product. The $-\mathrm{COO}$ absorption peak appeared at $1724.4 \mathrm{~cm}^{-1}$, while the $-\mathrm{CH}-\mathrm{N}^{+}\left(\mathrm{CH}_{3}\right)_{3}$ methylene bending vibration absorption peak and quaternary ammonium group absorption peak appeared at $1449.7 \mathrm{~cm}^{-1}$ and $950.7 \mathrm{~cm}^{-1}$ respectively, indicating that the DMC chain segments existed in the product. The $-\mathrm{SO}_{3}-$ absorption peak and vibration absorption peak appeared at $1192.2 \mathrm{~cm}^{-1}$ and $1042.5 \mathrm{~cm}^{-1}$, respectively, indicating that the product contained AMPS chain segments. The methyl and methylene asymmetric absorption peak appeared at $2942.9 \mathrm{~cm}^{-1}$. No $C=C$ absorption peak was observed within $1635-1620 \mathrm{~cm}^{-1}$, indicating that the three monomers were sufficiently copolymerized. The analysis was further confirmed in Figure 3, which showed the nuclear magnetic resonance spectrum (NMR) of SDCap. There was no absorption peak in the range of 6-7 ppm, indicating that there was no $\mathrm{C}=\mathrm{C}$ in the product and the three monomers were completely polymerized. The structure was characterized by NMR analysis, as shown in Figure 3.

The results of gel permeation chromatography test showed that the number-average molecular weight and weight-average molecular weight of SDCap were about 260,000 and 380,000, respectively. The molecular weight was much lower than that of the conventional encapsulator (over 2,000,000). 


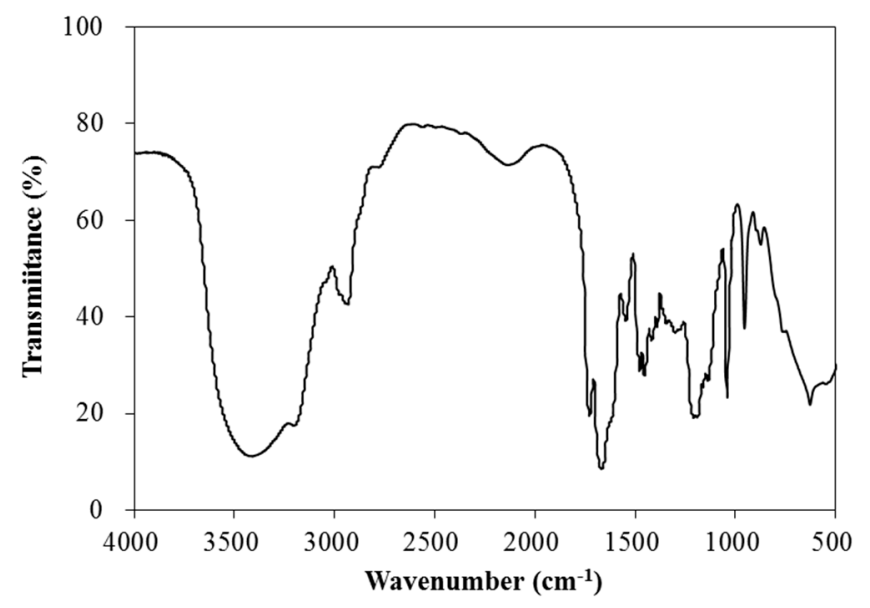

Figure 2. Analysis of SDCap Infrared spectrum.

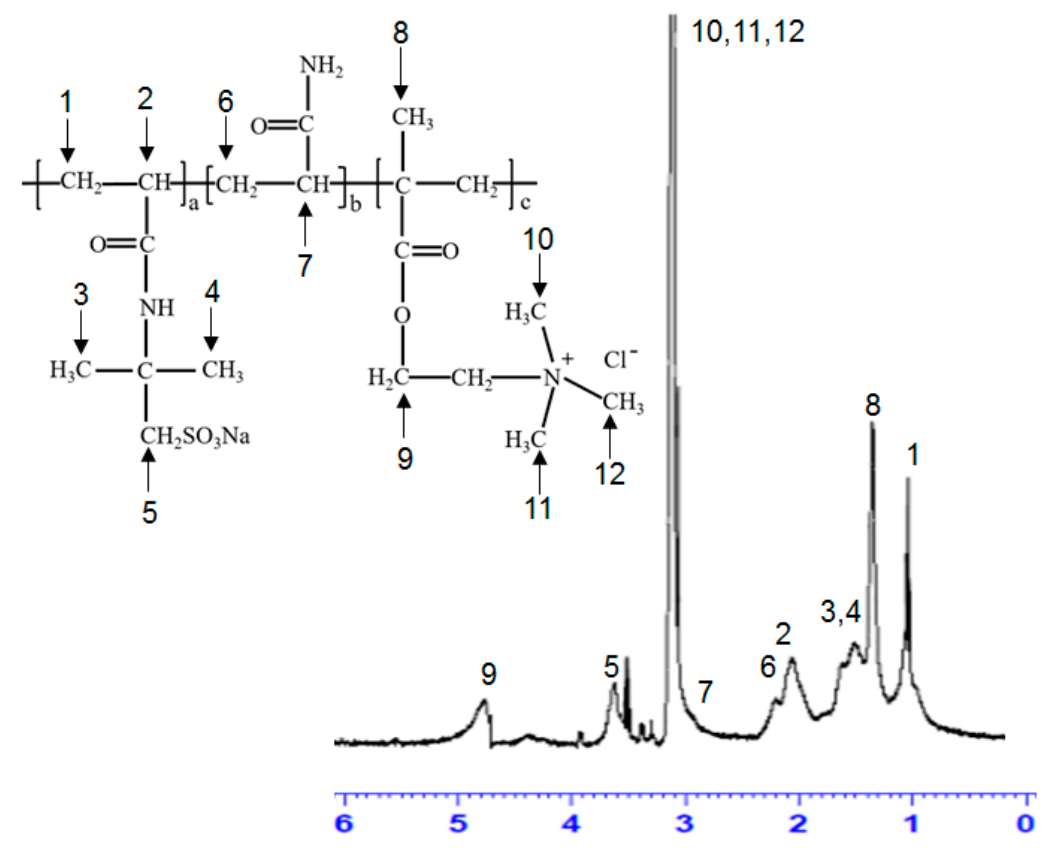

Figure 3. Analysis of SDCap nuclear magnetic resonance spectrum.

\subsection{Rheological Properties of Water-Based Drilling Fluids with SDCap under Deepwater Drilling Temperature}

WBDFs are multicomponent systems, so each component has to be compatible with others, otherwise the WBDF system would not be stable during drilling operations [38]. In order to evaluate the properties of SDCap in drilling fluid under field application conditions, two typical WBDFs were selected as the basic test fluids. WBDF-1 was a typical glycol/polymer WBDF, and WBDF-2 was a typical $\mathrm{KCl} / \mathrm{PHPA}$ WBDF. Both WBDFs have been widely used in onshore and offshore drilling [13,39], and the formulas are shown in Table 1 . In consideration of gas hydrate inhibition in deepwater drilling operations, at least a mass fraction of $10 \% \mathrm{NaCl}$ was added in the WBDFs. Therefore, good salt resistance was also required for SDCap. It is noticed that the encapsulators in WBDF-1 and WBDF-2 were FA-367 and PHPA, respectively. FA-367 was a widely used zwitterionic encapsulator, and PHPA was the representative of conventional encapsulator. In order to compare the properties of SDCap with FA-367 and PHPA, the $0.3 \%$ FA-367 in WBDF- 1 was replaced by $0.45 \%$ SDCap (WBDF-3), and the $0.25 \%$ PHPA in WBDF-2 was replaced by $0.375 \%$ SDCap (WBDF-4). The concentration of SDCap in WBDF-3 and WBDF-4 was 1.5 times of that of FA-367 and PHPA because the molecular weight 
of SDCap was far smaller than that of FA-367 and PHPA, and higher concentration of SDCap was required to maintain the desired encapsulation property. WBDF- 5 was a WBDF containing SDCap optimized in our laboratory, and it was expected to have more satisfactory low-temperature rheological property as well as other properties. The rheological properties of these five WBDFs are shown in Figure 4.

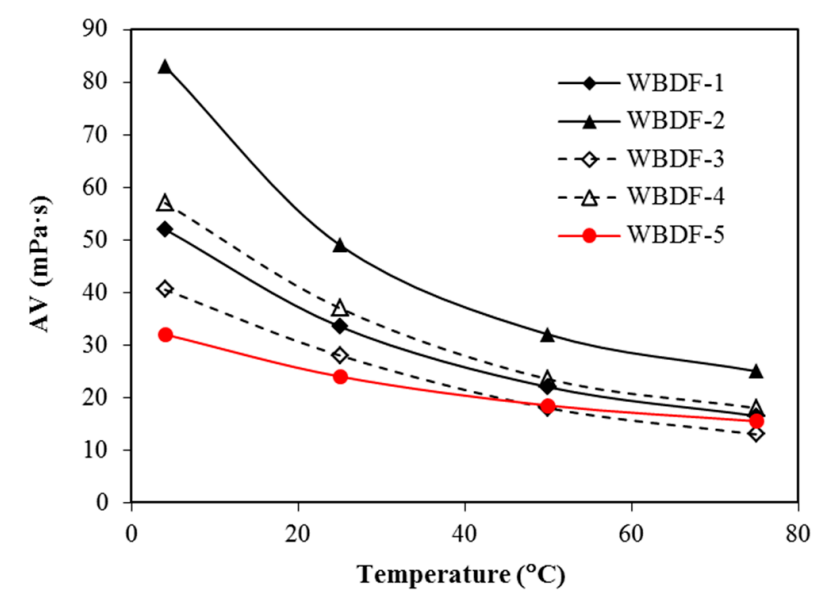

(a)

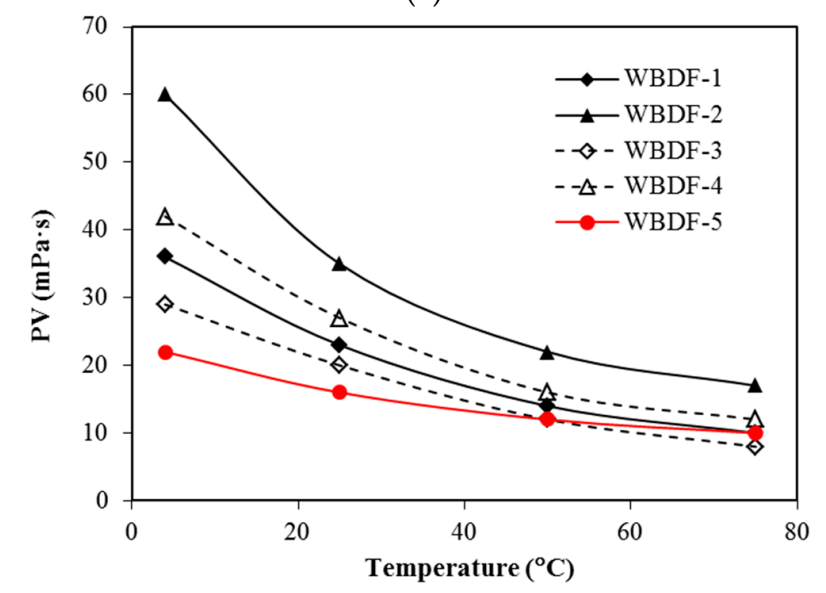

(b)

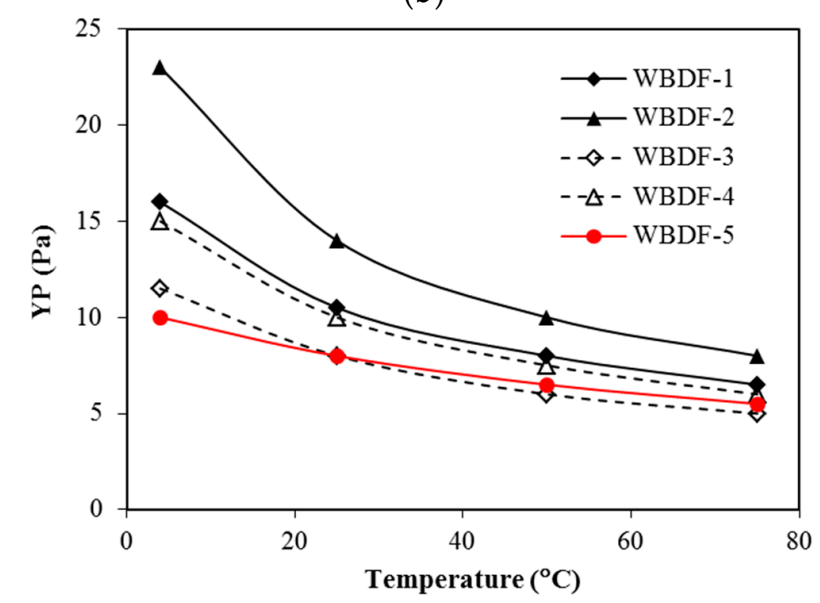

(c)

Figure 4. Rheological properties of $\mathrm{WBDFs}$ at the temperature range $4-75{ }^{\circ} \mathrm{C}$ : (a) changes in $\mathrm{AV}$ (apparent viscosity) as a function of temperature; (b) changes in PV (plastic viscosity) as a function of temperature; and (c) changes in YP (yield point) as a function of temperature. 
Table 1. Composition of the WBDFs (water-based drilling fluids).

\begin{tabular}{|c|c|c|c|c|c|c|}
\hline \multirow{2}{*}{ Component } & \multirow{2}{*}{ Function } & \multicolumn{5}{|c|}{ Mass Fraction/\% } \\
\hline & & WBDF-1 & WBDF-2 & WBDF-3 & WBDF-4 & WBDF-5 \\
\hline bentonite & filtrate reducer and viscosifier & 4.0 & 4.0 & 4.0 & 4.0 & 2.0 \\
\hline PHPA & encapsulator & & 0.25 & & & \\
\hline FA-367 & encapsulator & 0.3 & & & & \\
\hline SDCap & encapsulator & & & 0.45 & 0.375 & 0.35 \\
\hline $\mathrm{XC}$ & viscosifier & & 0.1 & & 0.1 & 0.15 \\
\hline PAC-LV & filtrate reducer & 0.5 & 0.6 & 0.5 & 0.6 & \\
\hline CMC-LV & filtrate reducer & & & & & 0.5 \\
\hline starch & filtrate reducer & 1.0 & & 1.0 & & \\
\hline SMP & filtrate reducer & & 4.0 & & 4.0 & 4.5 \\
\hline polyamine & shale inhibitor & & & & & 2.0 \\
\hline Polyglycol & shale inhibitor & 3.0 & & 3.0 & & \\
\hline $\mathrm{KCl}$ & shale inhibitor & 3.0 & 4.0 & 3.0 & 4.0 & 4.0 \\
\hline $\mathrm{NaCl}$ & hydrate inhibitor & 10.0 & 10.0 & 10.0 & 10.0 & 20.0 \\
\hline
\end{tabular}

The results showed that, for all tested WBDFs, the rheological parameters obviously increased as the temperature reduced. Particularly, when the temperature was reduced from 25 to $4{ }^{\circ} \mathrm{C}$, the increase in rheological parameter was more apparently, which was indicated by the more sharp slope of the rheology-temperature curve from 25 to $4{ }^{\circ} \mathrm{C}$. This low temperature interval is just the essential difference between deepwater drilling and onshore or offshore drilling, and it causes significant thickening of the drilling fluids. Therefore, we have to pay special attention to the rheological properties at $25-4{ }^{\circ} \mathrm{C}$. The ratios of rheological parameters at $4{ }^{\circ} \mathrm{C}$ and $25^{\circ} \mathrm{C}$ were used to describe the thickening of the drilling fluid at a low temperature. The AV represents the total viscosity of the drilling fluid and is the sum of PV and YP. PV represents the viscosity resulting from internal friction, while YP represents the viscosity generated by formations of grid structures among clay particles and high molecular polymers.

For WBDF-1, the AV at $4{ }^{\circ} \mathrm{C}$ was $52 \mathrm{mPa} \cdot \mathrm{s}$. The $\mathrm{AV}\left(4{ }^{\circ} \mathrm{C}\right) / \mathrm{AV}\left(25^{\circ} \mathrm{C}\right)$ ratio was $1.55 ; \mathrm{PV}\left(4{ }^{\circ} \mathrm{C}\right) /$ $\mathrm{PV}\left(25^{\circ} \mathrm{C}\right)$ ratio was 1.57 ; and the $\mathrm{YP}\left(4^{\circ} \mathrm{C}\right) / \mathrm{YP}\left(25^{\circ} \mathrm{C}\right)$ ratio was 1.52 . When $0.3 \% \mathrm{FA}-367$ was replaced by $0.45 \%$ SDCap, the AV of the drilling fluid (WBDF-3) was reduced by $22.1 \%$ (from $52 \mathrm{mPa} \cdot \mathrm{s}$ to $40.5 \mathrm{mPa} \cdot \mathrm{s})$. For WBDF-3, the $\mathrm{AV}\left(4^{\circ} \mathrm{C}\right) / \mathrm{AV}\left(25^{\circ} \mathrm{C}\right)$ ratio was $1.45 ; \mathrm{PV}\left(4{ }^{\circ} \mathrm{C}\right) / \mathrm{PV}\left(25^{\circ} \mathrm{C}\right)$ ratio was 1.45 ; and the $\mathrm{YP}\left(4^{\circ} \mathrm{C}\right) / \mathrm{YP}\left(25^{\circ} \mathrm{C}\right)$ ratio was 1.44 . All ratios of rheological parameters at $4{ }^{\circ} \mathrm{C}$ and $25{ }^{\circ} \mathrm{C}$ were reduced, indicating the thickening of the drilling fluid at a low temperature was mitigated using SDCap instead of FA-367. For WBDF-2, the AV at $4{ }^{\circ} \mathrm{C}$ was up to $83 \mathrm{mPa} \cdot \mathrm{s}$. The $\mathrm{AV}\left(4{ }^{\circ} \mathrm{C}\right) / \mathrm{AV}\left(25^{\circ} \mathrm{C}\right)$ ratio was 1.69; $\mathrm{PV}\left(4{ }^{\circ} \mathrm{C}\right) / \mathrm{PV}\left(25^{\circ} \mathrm{C}\right)$ ratio was 1.71 ; and the $\mathrm{YP}\left(4{ }^{\circ} \mathrm{C}\right) / \mathrm{YP}\left(25^{\circ} \mathrm{C}\right)$ ratio was 1.64 . When $0.25 \%$ PHPA was replaced by $0.375 \%$ SDCap, the AV of the drilling fluid (WBDF-4) was reduced by $31.3 \%$ (from $83 \mathrm{mPa} \cdot \mathrm{s}$ to $57 \mathrm{mPa} \cdot \mathrm{s})$. For WBDF-4, the $\mathrm{AV}\left(4{ }^{\circ} \mathrm{C}\right) / \mathrm{AV}\left(25^{\circ} \mathrm{C}\right)$ ratio was $1.54 ; \mathrm{PV}\left(4^{\circ} \mathrm{C}\right) / \mathrm{PV}\left(25^{\circ} \mathrm{C}\right)$ ratio was 1.56; and the $\mathrm{YP}\left(4^{\circ} \mathrm{C}\right) / \mathrm{YP}\left(25^{\circ} \mathrm{C}\right)$ ratio was 1.50 . Therefore, using SDCap instead of PHPA also mitigated the thickening effect of the drilling fluid at a low temperature.

For WBDF-5 which was expected to be a drilling fluid with better rheological property, the AV, PV and $\mathrm{YP}$ at $4{ }^{\circ} \mathrm{C}$ were $32 \mathrm{mPa} \cdot \mathrm{s}, 22 \mathrm{mPa} \cdot \mathrm{s}$, and $10 \mathrm{~Pa}$, respectively, and were all lower than that of other four WBDFs. The $\mathrm{AV}\left(4{ }^{\circ} \mathrm{C}\right) / \mathrm{AV}\left(25^{\circ} \mathrm{C}\right)$ ratio was 1.33 ; $\mathrm{PV}\left(4{ }^{\circ} \mathrm{C}\right) / \mathrm{PV}\left(25^{\circ} \mathrm{C}\right)$ ratio was 1.38 ; and the $\mathrm{YP}\left(4^{\circ} \mathrm{C}\right) / \mathrm{YP}\left(25^{\circ} \mathrm{C}\right)$ ratio was 1.25 . In comparison, the $\mathrm{AVs}$ of the two conventional WBDFs (WBDF-1 and WBDF-2) were $52 \mathrm{mPa} \cdot \mathrm{s}$ and $83 \mathrm{mPa} \cdot \mathrm{s}$. The AV of WBDF- 5 was only $61 \%$ and $39 \%$ of that of the conventional WBDFs, respectively. The $\mathrm{AV}\left(4^{\circ} \mathrm{C}\right) / \mathrm{AV}\left(25^{\circ} \mathrm{C}\right)$ ratios of the two conventional WBDFs were 1.55 and 1.69 , respectively; the $\mathrm{PV}\left(4^{\circ} \mathrm{C}\right) / \mathrm{PV}\left(25^{\circ} \mathrm{C}\right)$ ratios were 1.57 and 1.71 , respectively; and the $\mathrm{YP}\left(4^{\circ} \mathrm{C}\right) / \mathrm{YP}\left(25^{\circ} \mathrm{C}\right)$ ratios were 1.52 and 1.64 , respectively. Therefore, all the ratios of rheological parameters at $4{ }^{\circ} \mathrm{C}$ and $25^{\circ} \mathrm{C}$ for WBDF- 5 were much lower than that of the conventional WBDFs, indicating this optimized WBDF had better low-temperature rheology. Moreover, the curves of AV, PV and $\mathrm{YP}$ with temperature in Figure 4 were more stable in the temperature range $4-75^{\circ} \mathrm{C}$, indicating 
that its rheological properties were more independent on temperature under the deepwater drilling conditions, thus reducing the risk of rheology-related problems.

\subsection{Shale Inhibition Properties of Water-Based Drilling Fluid with SDCap}

\subsubsection{Inhibition on Shale Hydration Dispersion}

The shale recovery rate test can reflect the encapsulation effect of encapsulators on clay particles. A high recovery rate implies the strong shale inhibition property of drilling fluid. Figure 5 shows the results of shale recovery rate tests with the five WBDFs. The recovery rates of shales from the South China Sea (shale \#1) and Bohai Bay (shale \#2) were only $4.2 \%$ and $15.7 \%$ in pure water, respectively, indicating that the shales were highly prone to hydration dispersion and were hard recover, particularly for deepwater wells. Therefore, wellbore instability occurred easily, and the rheological and filtration properties of drilling fluid were also impacted due to the dispersed clay particles. The WBDFs significantly increased the recovery rate. For shale \#1 from deepwater wells, the recovery rates were $75.4 \%, 68.2 \%, 77.5 \%$, and $72.0 \%$ for WBDF-1, WBDF-2, WBDF-3, and WBDF-4, respectively. For shale $\# 2$, the recovery rates were $83.5 \%, 79.3 \%, 87.9 \%$, and $83.8 \%$, respectively. For WBDF-5, the recovery rates for shale \#1 and shale \#2 were $82.2 \%$ and $89.3 \%$, respectively, indicating its strong shale inhibition property. The results showed that SDCap was compatible with the WBDFs, and the recovery rate was increased when using SDCap instead of conventional encapsulator in WBDFs. Therefore, it could effectively inhibit the hydration dispersion of shales.

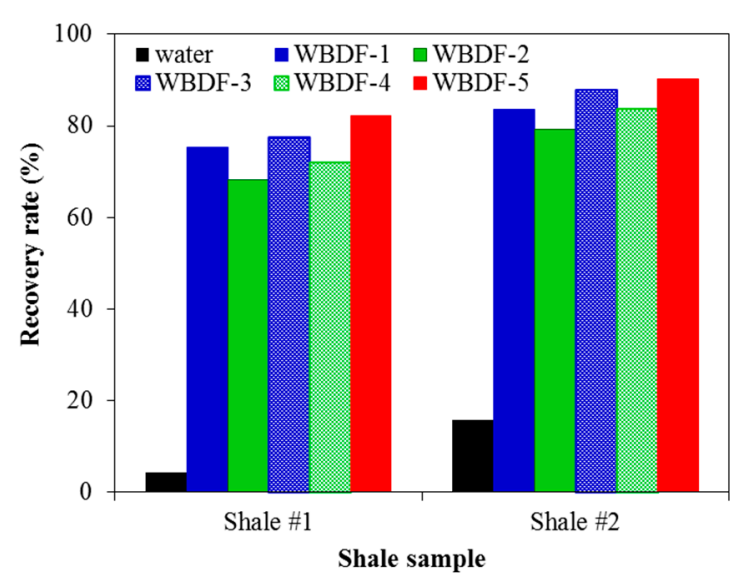

Figure 5. Shale recovery rates for different WBDFs.

\subsubsection{Shale Swelling Tests}

The encapsulator can adsorb on the clay particles on the wellbore surface, and the water molecules entering inside the wellbore rocks can be slowed down. Therefore, the encapsulator also has a certain capability of inhibiting the swelling of shale. Due to this reason, the shale swelling tests were also conducted to evaluate the inhibition property of the encapsulators, and the results were shown in Figure 6. It was found that the swelling rate of clay sample in pure water within $8 \mathrm{~h}$ was up to $40.8 \%$, indicating that the clay sample was highly prone to hydration swelling. In comparison, the swelling rate were $8.8 \%, 7.3 \%, 8.3 \%, 8.0 \%$ and $7.7 \%$ for WBDF-1, WBDF-2, WBDF-3, WBDF-4, and WBDF-5, respectively, indicating all the WBDFs could effectively inhibit the swelling of clay, and their inhibition effects were very similar.

Based on the results of shale inhibition tests and rheological property tests, the WBDF with SDCap had strong shale inhibition property, and had much better low-temperature rheological property than WBDFs with FA-367 and PHPA, even the concentration of SDCap was 1.5 times of that of FA-367 and PHPA. Therefore, using SDCap as the encapsulator in deepwater drilling fluid can both improve the 
low-temperature rheological property and shale inhibition property. In addition, SDCap has good salt resistance performance indicated by its stable properties in the presence of $10-20 \% \mathrm{NaCl}$.

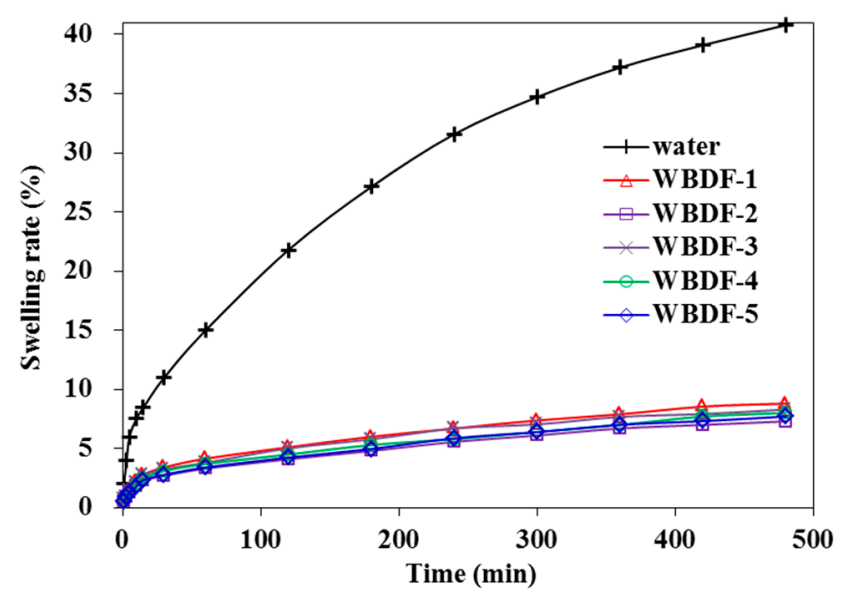

Figure 6. Swelling rates of samples in different WBDFs.

\subsubsection{Shale Inhibition Mechanism of SDCap with Low-Molecular-Weight}

Adsorption of SDCap on sodium bentonite:

The adsorption isotherm of SDCap is illustrated in Figure 7. It was found that SDCap could effective get adsorbed onto the clay surface. As the concentration of SDCap increased, the adsorbance increased significantly. The absorption capacity is the primary reason for the inhibition performance of SDCap. During drilling, when the drilling fluid containing SDCap interact with clay particles on wellbore or in drilling cuttings, through both the hydrogen bonding between the amide group and clay, and the electrostatic interaction between cationic group and clay, SDCap can be adsorbed on the surface of clay particles and does not fall off easily. Therefore, it inhibits the clay hydration dispersion, thus maintaining the wellbore stability and keeping the integrity of drill cuttings.

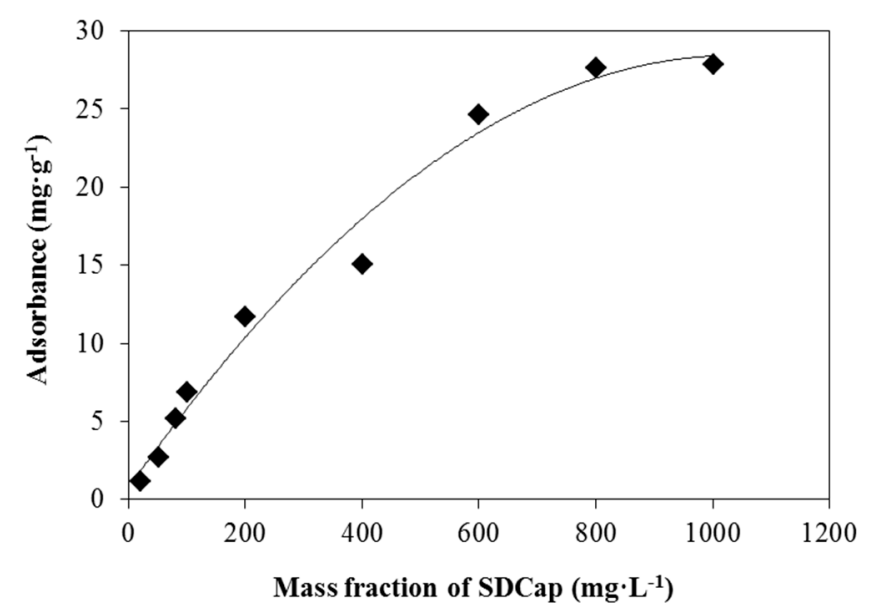

Figure 7. Variations of adsorbance of SDCap on clay particles as a function of concentration.

Analysis on clay particle size distribution:

Figure 8 shows the variations of distributions of the bentonite particle size in the presence of different concentration of SDCap. After adding SDCap, the size of bentonite particles obviously increased. $\mathrm{D}_{50}$ of bentonite suspension without SDCap was $11.1 \mu \mathrm{m}$, while that of suspension with 
$0.5 \%$ SDCap was $131.3 \mu \mathrm{m}$, indicating the addition of $0.5 \%$ SDCap increased the $\mathrm{D}_{50}$ of bentonite suspensions by more than 10 times. This demonstrated that the dispersed bentonite particles were wrapped together by SDCap, and were not easily dispersed in the drilling fluid. The results also reflected the strong adsorption capacity of SDCap.

Zeta potential analysis:

The results of zeta potential tests in Figure 9 showed that the addition of SDCap did not significantly impact the surface charges of clay for it was a zwitterionic polymer with both cationic and anionic groups (sulfonic acid groups). The cationic groups helped SDCap get adsorbed onto the surface of clay particles by electrostatic adsorption, while the effect of electrical neutralization was not apparent, thus avoiding the excessive electrical neutralization or even electrical reversal caused by cationic polymer which resulted in serious flocculation of drilling fluid (shown in Figure 10).

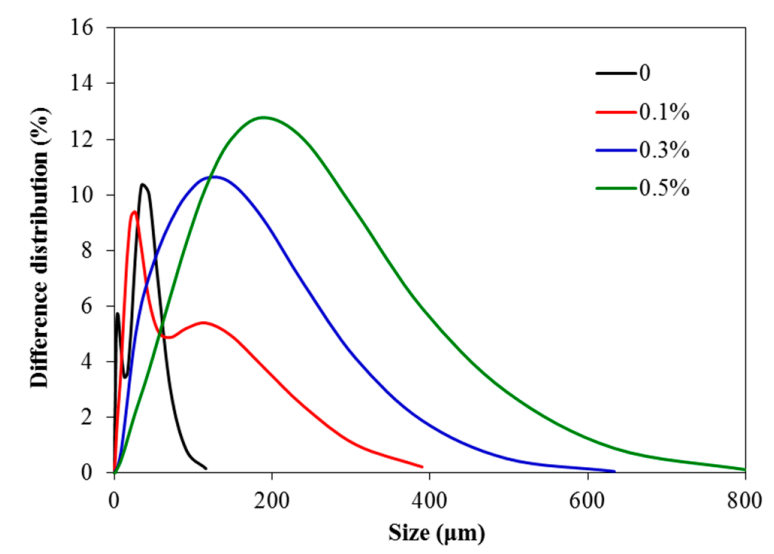

Figure 8. Clay particle size distribution in the presence of different concentration of SDCap.

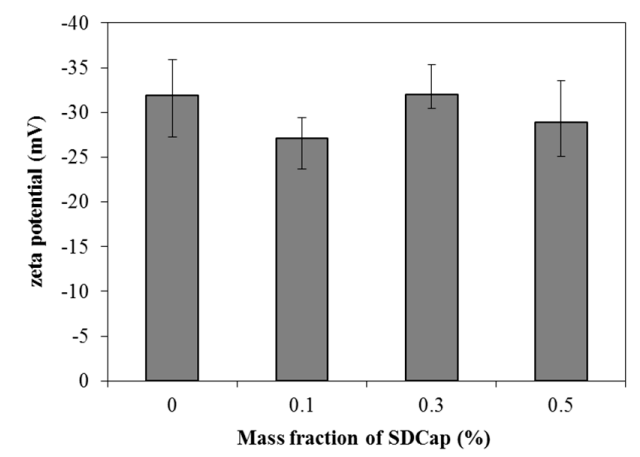

Figure 9. Variations of zeta potential as a function of concentration of SDCap.

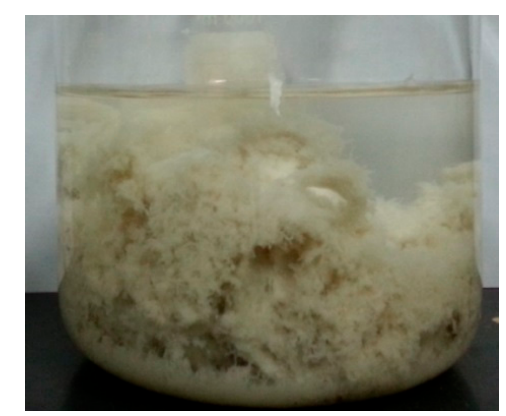

Figure 10. Flocculation of $4 \%$ bentonite suspension caused by addition of cationic polymer encapsulator. 


\subsection{Filtration Properties of Water-Based Drilling Fluid with SDCap}

Figure 11 shows the results of API and HTHP filtration tests of different WBDFs. In API filtration tests, the filtrate volume was $6.6 \mathrm{~mL}$ for WBDF-1, while that of WBDF-3 was $5.7 \mathrm{~mL}$, indicating that the filtration property of WBDF was improved by using $0.45 \%$ SDCap instead of $0.3 \%$ FA-367. The filtrate volume was reduced from $3.7 \mathrm{~mL}$ to $3.5 \mathrm{~mL}$ when $0.25 \%$ PHPA was replaced by $0.375 \%$ SDCap (WBDF-2 and SBDF-4). The filtrate volume of the optimized WBDF-5 was $4.8 \mathrm{~mL}$. In general, the API filtrate volume lower than $5 \mathrm{~mL}$ could meet the requirement of drilling operations. In HTHP filtration tests, the filtrate volumes were apparently larger than that in API filtration tests for the high temperature and high pressure influence the quality of the filter cake and promote the invasion of drilling fluid filtrates into the wellbore. The HTHP filtrate volume of WBDF-1 was up to $24.2 \mathrm{~mL}$. The WBDF-3 still had lower HTHP filtrate volume than WBDF-1, indicating that the addition of SDCap also improved the filtration property of WBDF under HTHP condition. The HTHP filtrate volumes of WBDF-2 and WBDF-4 were very similar. The HTHP filtrate volume of WBDF- 5 was $15.8 \mathrm{~mL}$, which was the smallest among these five WBDFs.

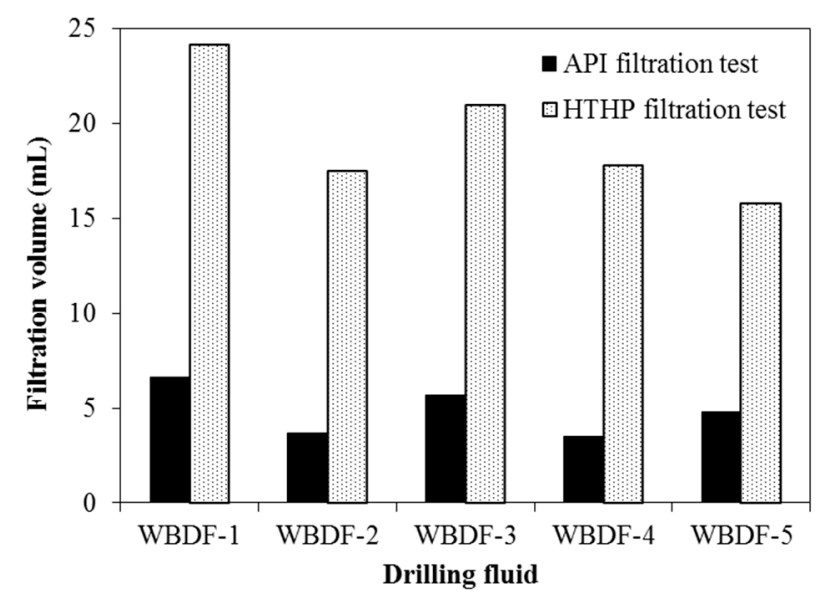

Figure 11. Filtration volumes with different WBDFs.

In order to further investigate the effect of SDCap on the filtration property of WBDF, the micro-structure of the filter cake which was formed by drilling fluid on the surface of filter paper in the API filtration tests was investigated using SEM analysis, as shown in Figure 12. In order to eliminate the influence of other additives on the characterization of the structure, $4 \%$ bentonite suspension containing only encapsulator was investigated. The filtrate volume in the API filtration tests was also measured. The SEM photos clearly showed the micro-structures of the filter cakes formed by different test fluids. For $4 \%$ bentonite suspension without encapsulator, it could not form a fine filter cake, and the surface of the filter cake was very coarse. There were lots of pores and fractures in the filter cake, as shown in Figure 12a,b. Therefore, the filtrates of the drilling fluid easily invade inside the rock formation in wellbore, resulting in hydration swelling and dispersion of shales. The filtrate volume of the API filtration tests could confirm the analysis for all the test fluid was leaking and the filtrate volume was large than $200 \mathrm{~mL}$, indicating the very poor quality of the filter cake. Therefore, filtrate reducers have to be used. The filter cake formed by $4 \%$ bentonite suspension with $0.3 \%$ PHPA was better than that formed by bentonite suspension, but it was still not satisfactory, as shown in Figure 12c,d. Owing to the absorption of PHPA on clay particles in the filter cake, the filter cake was tighter with smoother surface than that formed by $4 \%$ bentonite suspension without encapsulator. However, there were still lots of pores and fractures, and the flocculation could be observed which would result in uneven surface of filter cake. The filtrate volume was up to $64.0 \mathrm{~mL}$. In comparison, a tight filter cake with smooth surface was formed by $4 \%$ bentonite suspension containing $0.3 \%$ SDCap, as shown in Figure 12e,f, and the filter volume was $29.6 \mathrm{~mL}$. Very tight filter cake surface was observed, 
even in the SEM photo with 5000-fold magnification. The molecular chain was short and the adsorption capacity was strong, so clay particles with adsorbed SDCap molecules were evenly dispersed on the surface of wellbore without apparent flocculation, forming tight filter cake. Therefore, the addition of SDCap improved the filtration property of WBDF, thus mitigating the wellbore instability problems caused by the invasion of drilling fluid filtrates.

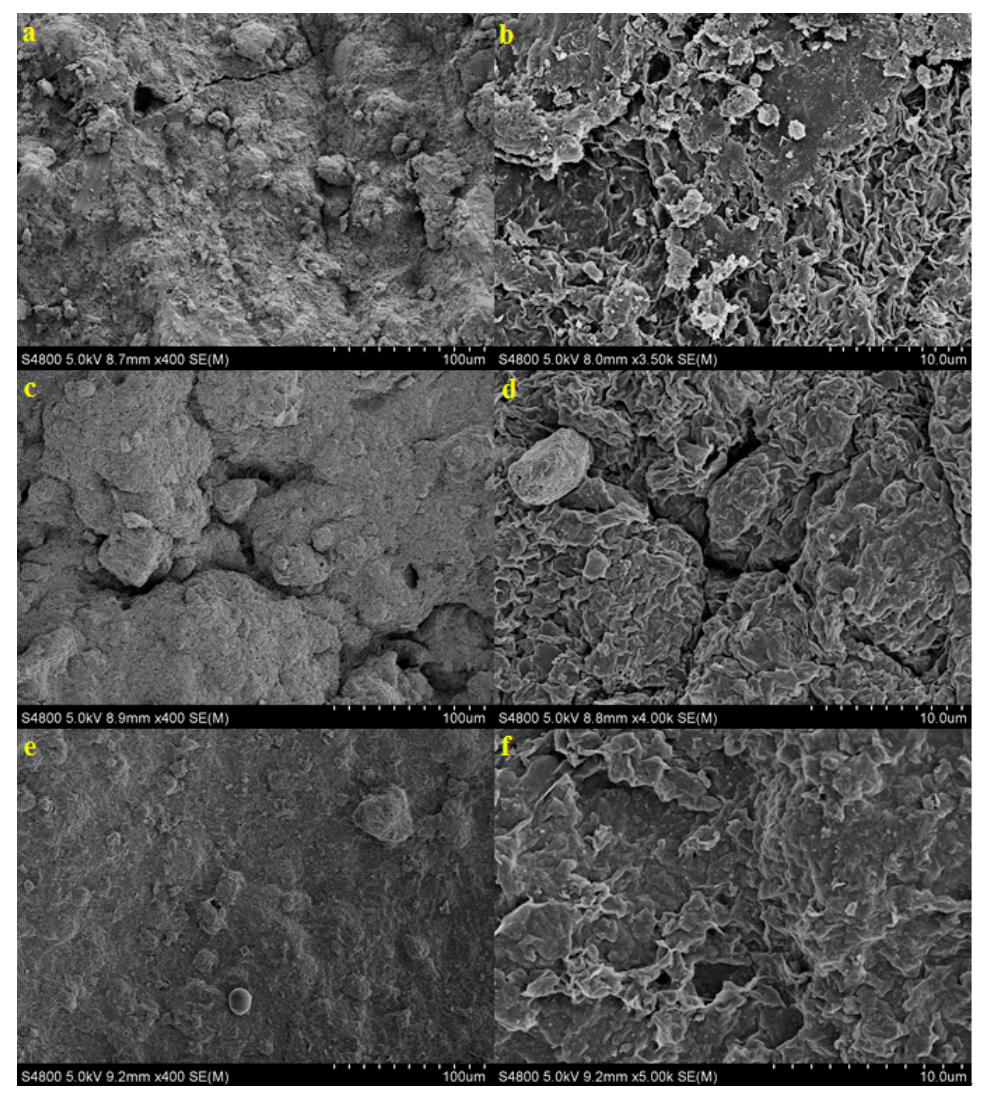

Figure 12. SEM photos of filter cakes formed by different test fluids. (a) $4 \%$ bentonite suspension (400-fold magnification); (b) 4\% bentonite suspension (3500-fold magnification); (c) 4\% bentonite suspension with $0.3 \%$ PHPA (400-fold magnification); (d) $4 \%$ bentonite suspension with $0.3 \%$ PHPA (4000-fold magnification); (e) 4\% bentonite suspension with $0.3 \%$ SDCap (400-fold magnification); (f) $4 \%$ bentonite suspension with $0.3 \%$ SDCap (5000-fold magnification).

\section{Conclusions}

Zwitterionic polymer P(AM-DMC-AMPS) named SDCap was developed as a low-molecular-weight encapsulator for deepwater drilling fluid. The number-average and weight-average molecular weight of SDCap were about 260,000 and 380,000, respectively, much lower than that of the conventional encapsulator. In the deepwater drilling temperature range $4-75{ }^{\circ} \mathrm{C}$, the WBDF containing SDCap had lower and more stable rheological property than that containing conventional encapsulators PHPA and PA-367, because of its short molecular chains. The shale recovery rate of WBDF containing SDCap was higher than that of WBDFs containing conventional encapsulator, and the swelling rate of these WBDFs were similar, indicating the strong shale inhibition performance of SDCap although its molecular weight was low. In addition, SDCap improved the filtration property of WBDF by forming tight filter cake, and was completely compatible with other components in WBDFs for it was a zwitterionic polymer with low-molecular-weight. The strong shale inhibition property of SDCap owes to its adsorption on the surface of clay particle and wrapping effect through both hydrogen bonding and electrostatic interaction. An optimized WBDF containing SDCap was also presented and 
it performed better than other WBDFs. It was concluded that using SDCap instead of conventional encapsulators can maintain the wellbore stability and keep the integrity of drill cuttings by inhibiting shale dispersion, and prevent the drilling fluid from lost circulation and adhesion on the vibrating screen caused by the severe thickening at a low temperature.

Acknowledgments: This work was supported by the National Basic Research Program of China (2015CB251205), the National Natural Science Foundation of China (51374233 and 51474236), and the Postdoctoral Innovative Project Foundation of Shandong Province (No. 201602027).

Author Contributions: Xin Zhao, Zhengsong Qiu and Yongjun Zhang conceived and designed the experiments; Yongjun Zhang synthesized the encapsulator; Xin Zhao, Yongjun Zhang and Zhichuan Tang performed the evaluation experiments; Xin Zhao, Hanyi Zhong and Weian Huang analyzed the data; and Xin Zhao wrote the paper.

Conflicts of Interest: The authors declare no conflict of interest.

\section{Abbreviations}

\begin{tabular}{|c|c|}
\hline $\mathrm{AM}$ & acrylamide \\
\hline AMPS & 2-acrylamido-2-methylpropane sulfonic acid \\
\hline DMC & methacrylatoethyl trimethyl ammonium chloride \\
\hline PHPA & partially hydrolyzed polyacrylamide \\
\hline FA-367 & Commercial zwitterionic encapsulator \\
\hline WBDF & water-based drilling fluid \\
\hline API & American Petroleum Institute \\
\hline FT-IR & Fourier transformation infrared \\
\hline NMR & nuclear magnetic resonance \\
\hline SEM & Scanning electron microscopy \\
\hline AV & apparent viscosity, $\mathrm{mPa} \cdot \mathrm{s}$ \\
\hline PV & plastic viscosity, mPa.s \\
\hline YP & yield point, $\mathrm{Pa}$ \\
\hline$\theta 600$ & $600 \mathrm{r} \cdot \mathrm{min}^{-1}$ reading in the viscometer \\
\hline$\theta 300$ & $300 \mathrm{r} \cdot \mathrm{min}^{-1}$ reading in the viscometer \\
\hline НTHР & high temperature and high pressure \\
\hline
\end{tabular}

\section{References}

1. Zhuang, G.; Zhang, Z.; Fu, M.; Ye, X.; Liao, L. Comparative study on the use of cationic-nonionicorgano-montmorillonite in oil-based drilling fluids. Appl. Clay Sci. 2015, 116, 257-262. [CrossRef]

2. Liu, K.; Ostadhassan, M.; Bubach, B. Applications of nano-indentation methods to estimate nanoscale mechanical properties of shale reservoir rocks. J. Nat. Gas Sci. Eng. 2016, 35, 1310-1319. [CrossRef]

3. Van Oort, E. On the physical and chemical stability of shales. J. Pet. Sci. Eng. 2003, 38, 213-235. [CrossRef]

4. Chen, G.; Chenevert, M.E.; Sharma, M.M.; Yu, M. A study of wellbore stability in shales including poroelastic, chemical, and thermal effects. J. Pet. Sci. Eng. 2003, 38, 167-176. [CrossRef]

5. Zhong, H.; Qiu, Z.; Huang, W.; Cao, J. Shale inhibitive properties of polyether diamine in water-based drilling fluid. J. Pet. Sci. Eng. 2011, 78, 510-515. [CrossRef]

6. Herzhaft, B.; Peysson, Y.; Isambourg, P.; Delepoulle, A.; Abdoulaye, T. Rheological Properties of Drilling Muds in Deep Offshore Conditions. In Proceedings of the 2001 SPE/IADC Drilling Conference, Amsterdam, The Netherlands, 27 February-1 March 2001; Society of Petroleum Engineers: Richardson, TX, USA, 2001.

7. Knox, D.; Bulgachev, R.; Cameron, I. Defining Fragile-The Challenge of Engineering Drilling Fluids for Narrow Ecd Windows. In Proceedings of the 2015 SPE/IADC Drilling Conference and Exhibition, London, UK, 17-19 March 2015; Society of Petroleum Engineers: Richardson, TX, USA, 2015.

8. Wang, S.; Yuan, C.; Zhang, C.; Chen, L.; Liu, J. Rheological properties with temperature response characteristics and a mechanism of solid-free polymer drilling fluid at low temperatures. Appl. Sci. 2017, 7, 18. [CrossRef] 
9. Rojas, J.C.; Daugherty, W.T.; Irby, R.D.; Bern, P.A.; Romo, L.A.; Dye, W.M.; Greene, B.; Trotter, R.N. New Constant-Rheology Synthetic-Based Fluid Reduces Downhole Losses in Deepwater Environments. In Proceedings of the 2007 SPE Annual Technical Conference and Exhibition, Anaheim, CA, USA, 11-14 November 2007; Society of Petroleum Engineers: Richardson, TX, USA, 2007.

10. Ramirez, M.; Moura, E.; Aragao, A.; Taira, H. HPWBM as a Technical Alternative to Drill Challenging Wells Project: Lessons Learned in Deepwater Brazil. In Proceedings of the Latin American \& Caribbean Petroleum Engineering Conference, Buenos Aires, Argentina, 15-18 April 2007; Society of Petroleum Engineers: Richardson, TX, USA, 2007.

11. Dokhani, V.; Ma, Y.; Yu, M. Determination of equivalent circulating density of drilling fluids in deepwater drilling. J. Nat. Gas Sci. Eng. 2016, 34, 1096-1105. [CrossRef]

12. Marin, J.U.; Shah, F.; Serrano, M.A.; Jaramillo, A.; Arevalo, W.; Priandi, G.B. First Deepwater Well Successfully Drilled in Colombia with a High-Performance Water-Based Fluid. In Proceedings of the 2009 Latin American and Caribbean Petroleum Engineering Conference, Caragena, Colombia, 31 May-3 June 2009; Society of Petroleum Engineers: Richardson, TX, USA, 2009.

13. Zhong, H.; Qiu, Z.; Huang, W.; Huang, D.; Li, H. Successful application of unique polyamine high performance water-based drilling fluid in bohai bay shale formations. In Proceedings of the 2013 International Petroleum Technology Conference (IPTC 2013), Beijing, China, 26-28 March 2013.

14. Zhong, H.; Qiu, Z.; Zhang, D.; Tang, Z.; Huang, W.; Wang, W. Inhibiting shale hydration and dispersion with amine-terminated polyamidoamine dendrimers. J. Nat. Gas Sci. Eng. 2016, 28, 52-60. [CrossRef]

15. Kadaster, A.; Guild, G.; Hanni, G.; Schmidt, D. Field applications of phpa muds. SPE Drill. Eng. 1992, 7, 191-199. [CrossRef]

16. Jain, R.; Mahto, V. Evaluation of polyacrylamide/clay composite as a potential drilling fluid additive in inhibitive water based drilling fluid system. J. Pet. Sci. Eng. 2015, 133, 612-621. [CrossRef]

17. Lu, Y.H.; Chen, M.; Jin, Y.; An, S.; Xie, S.X.; Pan, D.X.; Yuan, J.B. The development and application of an environmentally friendly encapsulator eba-20. Pet. Sci. Technol. 2012, 30, 2227-2235. [CrossRef]

18. Kang, P.S.; Lim, J.S.; Huh, C. Artificial neural network model to estimate the viscosity of polymer solutions for enhanced oil recovery. Appl. Sci. 2016, 6, 188. [CrossRef]

19. Jain, R.; Mahto, V.; Mahto, T.K. Study of the effect of xanthan gum based graft copolymer on water based drilling fluid. J. Macromol. Sci. Part A 2014, 51, 976-982. [CrossRef]

20. Sun, Q.; Zhang, N.; Li, Z.; Wang, Y. Nanoparticle-stabilized foam for mobility control in enhanced oil recovery. Energy Technol. 2016, 4, 1084-1096. [CrossRef]

21. Luo, J.; Li, Z.; Li, H. Research and application of hem poly-amine drilling fluids used in deep water operation. Drill. Fluid Complet. Fluid 2014, 31, 20-23.

22. Jiang, G.; Xie, S.; Chen, M.; Xu, F.; Wang, F.; Liu, C. Research and application on an environmentally friendly coating agent coater-10 with temperature resistance and salt tolerance. Oil Drill. Prod. Technol. 2011, 33, 14-18.

23. Li, H.; Luo, J.; Li, Z.; TGeng, T.; Jing, P.; Huang, X. Research and evacuation of a low molecular encapsulator pf-cap for deep-water. Petrochem. Ind. Appl. 2013, 32, 91-93.

24. Zou, C.; Liang, M.; Chen, X.; Yan, X. B-cyclodextrin modified cationic acrylamide polymers for flocculating waste drilling fluids. J. Appl. Polym. Sci. 2014, 131, 93-98. [CrossRef]

25. Zhang, Y.; Miao, Z.; Zou, J. A new cation-modified al-polyacrylamide flocculant for solid-liquid separation in waste drilling fluid. J. Appl. Polym. Sci. 2015, 132, 41641. [CrossRef]

26. Michel, C.R.; Martínez, A.H.; Huerta-Villalpando, F.; Morán-Lázaro, J.P. Carbon dioxide gas sensing behavior of nanostructured gdcoo 3 prepared by a solution-polymerization method. J. Alloys Compd. 2009, 484, 605-611. [CrossRef]

27. Xie, B.; Liu, X.; Wang, H.; Zheng, L. Synthesis and application of sodium 2-acrylamido-2-methylpropane sulphonate/n-vinylcaprolactam/divinyl benzene as a high-performance viscosifier in water-based drilling fluid. J. Appl. Polym. Sci. 2016, 133. [CrossRef]

28. Ding, W.; Zhou, J.; Zeng, Y.; Wang, Y.-N.; Shi, B. Preparation of oxidized sodium alginate with different molecular weights and its application for crosslinking collagen fiber. Carbohydr. Polym. 2017, 157, 1650-1656. [CrossRef] [PubMed] 
29. Mao, H.; Qiu, Z.; Shen, Z.; Huang, W. Hydrophobic associated polymer based silica nanoparticles composite with core-shell structure as a filtrate reducer for drilling fluid at utra-high temperature. J. Pet. Sci. Eng. 2015, 129, 1-14. [CrossRef]

30. Zhang, S.; Sheng, J.J.; Qiu, Z. Maintaining shale stability using polyether amine while preventing polyether amine intercalation. Appl. Clay Sci. 2016, 132, 635-640. [CrossRef]

31. Baruah, A.; Chauhan, G.; Ojha, K.; Pathak, A. Phase behavior and thermodynamic and rheological properties of single-(sds) and mixed-surfactant (sds+ capb)-based fluids with 3-methylbutan-1-ol as the cosurfactant and pine oil as the organic phase. Ind. Eng. Chem. Res. 2014, 53, 19765-19774. [CrossRef]

32. Li, M.-C.; Wu, Q.; Song, K.; De Hoop, C.F.; Lee, S.; Qing, Y.; Wu, Y. Cellulose nanocrystals and polyanionic cellulose as additives in bentonite water-based drilling fluids: Rheological modeling and filtration mechanisms. Ind. Eng. Chem. Res. 2015, 55, 133-143. [CrossRef]

33. Fang, R.; Tian, W.; Chen, X. Synthesis of injectable alginate hydrogels with muscle-derived stem cells for potential myocardial infarction repair. Appl. Sci. 2017, 7, 252. [CrossRef]

34. Liu, K.; Ostadhassan, M. Microstructural and geomechanical analysis of bakken shale at nanoscale. J. Pet. Sci. Eng. 2017, 153, 133-144. [CrossRef]

35. Wang, Y.; Ge, J.; Zhang, W.; Zhang, G.; Lin, Y.; Song, K. Surface property and enhanced oil recovery study of foam aqueous dispersions comprised of surfactants-Organic acids-Nanoparticles. RSC Adv. 2016, 6, 113478-113486. [CrossRef]

36. Li, F.; Feng, Y.; Guo, Y.; Hu, X. Study on adsorption property of hydrophbically modified polyacrylamides on clay. Chem. Eng. Oil Gas 2002, 31, 263-265.

37. Wang, B.; Zhang, X.; Ji, W.; Ruan, Q.; Kuang, L. Adsorption and desorption characteristics of polyacrylamide on black soil. Chem. Eng. 2009, 37, 9-12.

38. Huang, M.; Kang, Y.; Long, X.; Wang, X.; Hu, Y.; Li, D.; Zhang, M. Effects of a nano-silica additive on the rock erosion characteristics of a sc-co2 jet under various operating conditions. Appl. Sci. 2017, 7, 153. [CrossRef]

39. Zhao, X.; Qiu, Z.; Huang, W.; Xu, J.; Sheng, J. Multifunctional properties of polyglycol in deepwater drilling fluids. Chem. Technol. Fuels Oils 2014, 50, 233-239. [CrossRef] 